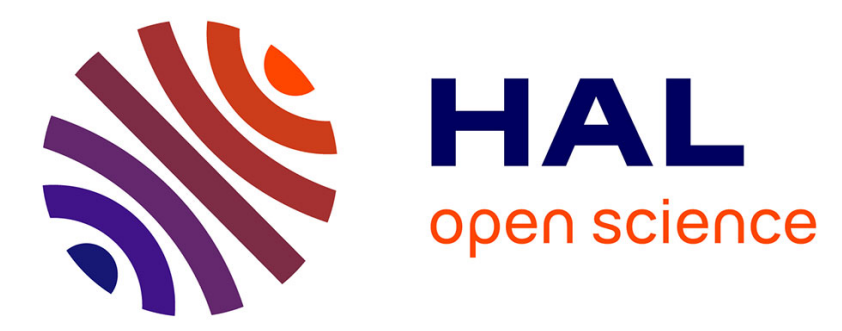

\title{
Comparison of densification kinetics of a TiAl powder by spark plasma sintering and hot pressing
}

\author{
Zofia Trzaska, Guillaume Bonnefont, Gilbert Fantozzi, Jean-Philippe
}

Monchoux

\section{- To cite this version:}

Zofia Trzaska, Guillaume Bonnefont, Gilbert Fantozzi, Jean-Philippe Monchoux. Comparison of densification kinetics of a TiAl powder by spark plasma sintering and hot pressing. Acta Materialia, 2017, 135, pp.1 - 13. 10.1016/j.actamat.2017.06.004 . hal-01726589

\section{HAL Id: hal-01726589 \\ https://hal.science/hal-01726589}

Submitted on 8 Mar 2018

HAL is a multi-disciplinary open access archive for the deposit and dissemination of scientific research documents, whether they are published or not. The documents may come from teaching and research institutions in France or abroad, or from public or private research centers.
L'archive ouverte pluridisciplinaire HAL, est destinée au dépôt et à la diffusion de documents scientifiques de niveau recherche, publiés ou non, émanant des établissements d'enseignement et de recherche français ou étrangers, des laboratoires publics ou privés. 


\title{
Comparison of densification kinetics of a TiAl powder
}

\section{by spark plasma sintering and hot pressing}

\author{
Zofia Trzaska $^{1,2}$, Guillaume Bonnefont ${ }^{3}$, Gilbert Fantozzi ${ }^{3}$, Jean-Philippe Monchoux ${ }^{1,2, *}$ \\ 1: CNRS; CEMES (Centre d'Elaboration de Matériaux et d'Etudes Structurales); \\ BP 94347, 29 rue J. Marvig, F-31055 Toulouse, France \\ 2: Université de Toulouse; UPS; F-31055 Toulouse, France \\ 3: MATEIS; INSA Lyon; 7 Avenue J. Capelle, F-69621 Villeurbanne, France \\ * To whom correspondence should be addressed. E-mail: monchoux @cemes.fr. Phone: +33 5 \\ 622579 79. Address: CEMES-CNRS UPR 8011, 29, rue Jeanne Marvig, BP 94347, 31055 \\ Toulouse cedex 4, France.
}

\begin{abstract}
Densification kinetics by spark plasma sintering (SPS) and hot pressing (HP) have been compared, under isothermal conditions and with heating rates of $20^{\circ} \mathrm{C} / \mathrm{min}$. Careful calibration of sample temperature has been carried out to obtain comparable results. In all cases, densification kinetics did not exhibit significant differences, ruling out any influence of the SPS current. The stress exponent $n$ and the activation energy $Q$ of the Norton law describing deformation at high temperature of the powder particles have been determined by isothermal experiments at different stresses and temperatures, respectively. The values obtained, $n=1.9 \pm 0.3$ and $Q=308 \pm 20 \mathrm{~kJ} / \mathrm{mol}$ for SPS, $n=1.5 \pm 0.3$ and $Q=276 \pm 40 \mathrm{~kJ} / \mathrm{mol}$ for HP, come close in both techniques. Using these values, anisothermal densification kinetics at heating rates of $20^{\circ} \mathrm{C} / \mathrm{min}$ and $100^{\circ} \mathrm{C} / \mathrm{min}$, typical of the SPS, could be analytically reproduced, using literature models. The activation parameters suggest that
\end{abstract}


SPS densification kinetics occurs by dislocation climb controlled by Al bulk diffusion, that is, by classical metallurgical mechanisms.

Keywords: spark plasma sintering; hot pressing; plasticity; titanium aluminides.

\section{Introduction}

This study reports on the densification kinetics of a TiAl powder by spark plasma sintering (SPS). This technique consists in uniaxially pressing powders in graphite molds heated by high intensity electric current pulses. This allows very fast heating rates, and thus densification [1] or synthesis [2] cycles lasting typically less than 1 hour, that is, up to 10 times less than that of the conventional processing techniques. Many studies have attributed to the electric current pulses an intrinsic contribution to the acceleration of the densification, different from the Joule effect, and several phenomena occurring at the necks between the powder particles were invoked. Local overheating by formation of arcs and plasmas between the particles has been postulated [3,4], and experimentally observed by optical microscopy [5] and by insitu atomic emission spectroscopy [6]. Given these sparking mechanisms, local melting phenomena occurring at the contact zones of powder particles in various materials have been observed [6-8], theoretically analyzed [9] and simulated [10]. Another localized electric effect put forward is that of an intensifying electric current density at the necks between the powder particles, which may cause these zones to melt $[11,12]$. Finally, very high current densities at the necks are believed to induce electromigration [13] or electroplasticity [14] phenomena, which are likely to accelerate densification kinetics. However, the above electrically-induced phenomena are still controversial, and assessment of their intrinsic contribution to the densification kinetics remains scarce. In the case of low electrical conductivity materials (eg, Zirconia), densification under isothermal conditions by means of SPS and by a current free technique, the hot pressing (HP), seems to exhibit close kinetics, even if slight differences in mechanisms have been reported [15]. For a material with 
a higher electrical conductivity (quasi-crystalline $\mathrm{AlCuFeB}$ ), densification experiments by means of SPS and HP have been carried out, but with different conditions, making comparisons difficult [16]. It was concluded that the sintering mechanisms were probably close in both techniques. Finally, a recent study has compared HP and SPS kinetics in isothermal and anisothermal conditions, with a highly conducting powder $(\mathrm{Cu})$, and with a calibration of the sample temperature between the two techniques. It was concluded that densification kinetics were identical, and that the SPS current had no intrinsic effect on densification [17].

Here, we investigate the intrinsic effect of the SPS current on the densification kinetics of an intermetallic conducting powder (TiAl, GE composition : $\mathrm{Ti}_{48.7} \mathrm{Al}_{47.3} \mathrm{Cr}_{1.9} \mathrm{Nb}_{2}$ ) by SPS and HP in isothermal and anisothermal conditions, with calibration of the sample temperature in both techniques. In addition, the macroscopic activation parameters are determined and compared to literature values. Finally, it is shown how the densification kinetics by SPS can be analytically determined, provided the activation parameters are accurately known. These results are important in our opinion, because shaping of TiAl alloys by SPS (for turbine blades applications for instance [18]) will require assessing the densification kinetics in sophisticated molds from the constitutive relations of the alloy at high temperature. Moreover, as the SPS route has shown these materials to exhibit interesting, not to say outstanding mechanical properties [18-23], these alloys are therefore suitable for high temperature applications in aircraft turbine blades or in turbochargers. Thus, the shaping issue will become increasingly important, and will necessitate basic inputs with respect to the densification kinetics.

\section{Experimental}

A spherical gas atomized $\mathrm{GE}$ TiAl powder $\left(\mathrm{Ti}_{48.7} \mathrm{Al}_{47.3} \mathrm{Cr}_{1.9} \mathrm{Nb}_{2}\right.$, Crucible $)$ of granulometry $c a .100-150 \mu \mathrm{m}$ has been employed. Prior to the experiments, the powder has 
been equilibrated at $1200^{\circ} \mathrm{C}$ for 5 min by SPS, but in a special mold in which no pressure and no electric current was applied to the powder. This allowed equilibration in vacuum of the particle microstructure by transformation of dendritic as-gas atomized metastable $\alpha$ [24] into equilibrium $\gamma+\alpha[20,25]$ microstructure. The aim of this procedure was to avoid that microstructure changes in the powder activated by temperature would superimpose and interfere to the phenomena activated in the SPS and HP experiments. Consequently, the microstructure of the powder particles consisted in an equilibrium near $\gamma$ microstructure containing $4 \%$ vol. of $\alpha_{2}$ phase which did not evolve during densification [26].

For both SPS and HP experiments, graphite molds about $20 \mathrm{~mm}$ in inner diameter were employed. However, the other dimensions of the molds were not the same. The molds used for HP, which were typical of this technique, had thicker walls than the molds used for the SPS experiments. The reason was that accidental breaking of the molds could have damaged the heating system of the HP, and had therefore to be absolutely avoided. These molds were not suitable for the SPS experiments, because there was a too high difference between the punch diameter $(20 \mathrm{~mm})$ and the outer diameter of the molds (between $65 \mathrm{~mm}$ and $73 \mathrm{~mm}$ ), which would have given strong electric current concentration in the punches, and therefore high thermal gradients in the samples and in the molds. Thus, the dimensions of the SPS and HP molds were as follows:

- SPS molds: inner diameter: $20.8 \mathrm{~mm}$, outer diameter: $40 \mathrm{~mm}$, height: $48 \mathrm{~mm}$.

- HP molds: inner diameter: $20.4 \mathrm{~mm}$, outer diameter: varying from $65 \mathrm{~mm}$ to $73 \mathrm{~mm}$, height: $120 \mathrm{~mm}$.

A graphite foil (Papyex) was employed, to ensure sealing and lubrication. Its thickness was $0.4 \mathrm{~mm}$ and $0.2 \mathrm{~mm}$ for the SPS and HP molds, respectively. Thus, in both cases, the sample diameter was $20 \mathrm{~mm}$. To obtain accurate densification curves, the ratio between final 
thickness and diameter of the sample had to be as low as possible, to minimize the friction of the powder on the lateral walls of the molds [27]. Then, $3.92 \mathrm{~g}$ of the equilibrated powder was introduced in the molds, giving a sample thickness at full density of $3 \mathrm{~mm}$. During the SPS cycle, the molds were surrounded by graphite felt, to limit the thermal gradients in the samples [28].

For the SPS experiments, a Sumitomo 2080 machine has been used. First, the chamber of the SPS was evacuated to $\approx 10 \mathrm{~Pa}$. The uniaxial pressure was set to the desired value $(25 \mathrm{MPa}$ to $75 \mathrm{MPa}$ ) and applied for one minute. While pressure was applied, the heating cycle was initiated. The samples were then heated to $570^{\circ} \mathrm{C}$ within $5 \mathrm{~min}$. This was followed by heating at $20^{\circ} \mathrm{C} / \mathrm{min}$ (some experiments were carried out at $100^{\circ} / \mathrm{min}$ ). This heating rate was selected to be the same as in the HP experiments, which is limited to $20^{\circ} \mathrm{C} / \mathrm{min}$. For the isothermal experiments, this heating was followed by a plateau of $1 \mathrm{~h}$ (some experiments have nonetheless been interrupted after $15 \mathrm{~min}$ and $30 \mathrm{~min}$ ) at constant sample temperatures between $865^{\circ} \mathrm{C}$ and $1075^{\circ} \mathrm{C}$. At the end of the cycle, the heating current was stopped and the pressure released. The cooling rate of the molds in the SPS chamber was about $150^{\circ} \mathrm{C} / \mathrm{min}$. For the anisothermal experiments, heating was maintained at $20^{\circ} \mathrm{C} / \mathrm{min}$ throughout the cycle, until a temperature of $\approx 1300^{\circ} \mathrm{C}$ was reached. Then, heating was halted. The temperature was measured on the external wall of the molds using an optical pyrometer, beginning at $570^{\circ} \mathrm{C}$. The pulse sequence of the SPS current was the common "12-2" type (12 current pulses and 2 timeouts). The current was measured by the magneto-electric sensor of the machine, which yields a value close to the average of the time-dependent signal of the current [29]. The current actually flowing through the sample has been estimated to $30 \%$ of the total SPS current, following the study by Misawa et al. on metallic materials [30]. Shrinkage of the sample due to densification was measured by the displacement of the lower punch with an accuracy of about $\pm 0.005 \mathrm{~mm}$. 
For the HP experiments, the equipment from the MATEIS laboratory was employed. It consisted of a uniaxial hot press Goliath (Stein Heurtey, Physiterm). The die containing the powder was externally heated with a graphite resistance. The maximum load applied to the punches was $200 \mathrm{kN}$ for a maximum temperature of about $2200^{\circ} \mathrm{C}$. Heating took place under vacuum $(\sim 10 \mathrm{~Pa})$. Temperature was measured on the surface of the mold using an optical pyrometer (beginning at $250^{\circ} \mathrm{C}$ ) and the temperature cycle was obtained by a $\mathrm{W}-\mathrm{Rh}$ thermocouple. All the anisothermal experiments were carried out with a heating rate of $20^{\circ} \mathrm{C} / \mathrm{min}$. The uniaxial pressure was set to the desired value identical to the SPS experiments (25 to $75 \mathrm{MPa}$ ) and applied in 3 minutes. At the end of a cycle, resistance heating was stopped and pressure released. The cooling rate of the die in the HP chamber was about $20^{\circ} \mathrm{C} / \mathrm{min}$. Displacement of the upper punch was measured by a wire potentiometer with a precision of about $\pm 0.01 \mathrm{~mm}$

Because temperatures in the SPS and HP experiments were measured on the external surface of the molds, the sample temperature was not known and had to be determined by calibration. This was performed by melting $\mathrm{Al}\left(660^{\circ} \mathrm{C}\right), \mathrm{Cu}\left(1085^{\circ} \mathrm{C}\right)$, and by using the change in $\mathrm{TiAl}$ microstructure at the $\alpha$ transus $\left(\gamma+\right.$ lamellar below $1335^{\circ} \mathrm{C}$, fully lamellar above $1335^{\circ} \mathrm{C}$ [28]). The onset of melting (see example of $\mathrm{Cu}$ melted by SPS in Fig. 1a), and the crossing of the $\alpha$ transus (see an example in HP experiment in Fig. 1b-c), could be determined within about $\pm 10^{\circ} \mathrm{C}$ and $\pm 12.5^{\circ} \mathrm{C}$, respectively. The calibration curves thus obtained, yielding the sample temperature $T_{\text {sample }}$ as a function of the temperature given by the pyrometer $T_{\text {pyro, }}$, are plotted in Fig. 2.

Quantitative determination of the relative density $D(\mathrm{t})=\rho_{(t)} / \rho_{\mathrm{th}}$, with $\rho_{(t)}$ : density of the sample at time $t$, and $\rho_{\text {th }}$ : theoretical density of the sample at full density $\left(=3.95 \mathrm{~g} / \mathrm{cm}^{3}\right.$ for TiAl), during the SPS and HP cycles were performed using the following expressions, which can be easily derived: 


$$
D_{\mathrm{f}}=\frac{\rho_{\mathrm{f}}}{\rho_{\mathrm{th}}}
$$

$$
\rho_{\mathrm{f}}=\frac{m}{v_{\mathrm{f}}}=\frac{m}{\pi \frac{\phi^{2}}{4} e_{\mathrm{f}}}
$$

With $D_{\mathrm{f}}$ : final relative density of the sample, $e_{\mathrm{f}}$ : final thickness of the sample, $d(\mathrm{t})$ and $d_{\mathrm{f}}$ : position at time $t$ and final position of the mobile punch of the SPS and HP, $\rho_{\mathrm{f}}$ final density, $m$ : mass of the sample, $v_{\mathrm{f}}$ : final volume of the sample, and $\phi$ : diameter of the sample (=20 mm). In the densification curve, the value of the final relative density of the sample $D_{\mathrm{f}}$ is denoted using a symbol. It has been geometrically determined by measuring $e_{\mathrm{f}}, \emptyset$ and $m$ and by using Eqs (2) and (3). To remove the contribution of the deformation of the graphite tools (elastic deformation due to applied pressure and thermal dilatation), punch displacement has been recorded in the conditions of the densification experiments, but without sample (blank test). Then, $d(\mathrm{t})=d_{\mathrm{p}}(\mathrm{t})-d_{\mathrm{b}}(\mathrm{t})$, with $d_{\mathrm{p}}(\mathrm{t})$ : un-corrected punch displacement in the densification experiments, and $d_{\mathrm{b}}(\mathrm{t})$ : punch displacement in the blank tests.

\section{Results}

The aim of this study was to compare the densification kinetics obtained by SPS and HP. Densification experiments in isothermal (at different temperatures and applied loads) and anisohtermal conditions have then been performed with both techniques.

\subsection{Isothermal conditions}

\subsubsection{Densification cycles}

Fig. 3a-b shows temperature (measured by pyrometer) and pressure profiles during SPS and HP densification cycles. Both profiles are very much alike, except for the temperature 
reading which begins at $570^{\circ} \mathrm{C}$ and $250^{\circ} \mathrm{C}$ in the SPS and $\mathrm{HP}$ experiments, respectively. This does not impact the results, because up to about $800^{\circ} \mathrm{C}$, no densification occurs in TiAl [26]. Another difference is a larger contribution of the deformation of the graphite tools, $d_{\mathrm{b}}$, by HP than by SPS (Fig. 3a-b). This is due to the larger size of the HP molds. Finally, the current density flowing through the sample $J$ and the voltage $U$ tend to exhibit constant values during the isothermal plateau of the SPS experiments (Fig. 3c). These values increase with plateau temperature: $J$ and $U$ go from $57 \mathrm{~A} / \mathrm{cm}^{2}$ to $74 \mathrm{~A} / \mathrm{cm}^{2}$, and from $1.68 \mathrm{~V}$ to $2.14 \mathrm{~V}$, when temperature increases from $\mathrm{T}_{\text {sample }}=865^{\circ} \mathrm{C}$ to $\mathrm{T}_{\text {sample }}=1075^{\circ} \mathrm{C}$, respectively.

\subsubsection{Densification curves}

To draw densification curves, the isothermal parts (from $t=0$ ) of the SPS and HP cycles have been selected, and $D$ has been calculated using Eqs. (1), (2) and (3). Figs. 4 and 5 give isothermal SPS and HP densification curves obtained for sample temperatures between $865^{\circ} \mathrm{C}$ and $1075^{\circ} \mathrm{C}$, and for applied pressures between $33 \mathrm{MPa}$ and $75 \mathrm{MPa}$. In one case $\left(\mathrm{T}_{\text {sample }}=969^{\circ} \mathrm{C}, \mathrm{P}=50 \mathrm{MPa}\right.$, Fig. $\left.4 \mathrm{c}\right)$, the experiments have been repeated, and geometric measurements of the relative density after experiments interrupted at $t=0.25 \mathrm{~h}$ and $t=0.5 \mathrm{~h}$ (shown in Fig. 4c by symbols), have been carried out. These results show that the accuracy of the absolute value of $D$ is about \pm 0.02 . The striking feature of these results is that the densification kinetics by SPS and HP are close, the differences being of the order of the data scattering.

\subsection{Anisothermal conditions}

\subsubsection{Densification cycle}

Fig. 6a shows the time dependence of the parameters during SPS and HP cycles with identical heating rates of $20^{\circ} \mathrm{C} / \mathrm{min}$. It can be seen that the profiles of sample temperatures (corrected from pyrometer measurement using calibration curves shown in Fig. 2) in the SPS 
and HP experiments present reasonably similar evolutions. The dwell pressure is reached within $\approx 2$ min by SPS and 10 min by HP, but this difference has no influence of the results, because significant densification occurs only after $10 \mathrm{~min}$ (Fig. 6b). In the SPS experiments, the current density in the sample and voltage at the final temperature $\left(\mathrm{T}_{\text {sample }}=1343^{\circ} \mathrm{C}\right)$ are $112 \mathrm{~A} / \mathrm{cm}^{2}$ (Fig. 6a) and 3.44 V (not shown), respectively.

\subsubsection{Densification curves}

SPS and HP densification curves obtained in the aforementioned conditions are shown in Fig. 6b. Considering that the experiments have been conducted in two different laboratories using different graphite tools geometries, it can be inferred that both curves are reasonably similar. Hence, the striking feature is that the densification kinetics by SPS is not much faster than by HP.

\section{Analysis of the results}

\subsection{Determination of stress exponent and activation energy}

By using the isothermal densification curves at different applied stresses, and different temperatures, it is possible to determine the stress exponent $n$ and the activation energy $Q$, respectively, assuming that densification occurs by power-law creep. In this case, the deformation rate $\dot{\varepsilon}$ of the material making up the powder particles under a stress $\sigma$ follows a Norton law:

$$
\dot{\varepsilon}=A_{0} \exp \left(-\frac{Q}{R T}\right) \sigma^{n}
$$

with $A_{0}$ : material constant. Then, the densification rate $\dot{D}$ follows the relations given below, provided the contributions of capillary forces and gas trapped in the pores on the effective pressure are disregarded [31, 32]: 


$$
\sigma=G_{2}(D) P
$$

with, for $D<0.9$ :

$$
\begin{gathered}
G_{1}(D)=5,3\left(D^{2} D_{0}\right)^{1 / 3} \frac{1}{\sqrt{3}}\left(\frac{D-D_{0}}{1-D_{0}}\right)^{1 / 2} \\
G_{2}(D)=\frac{1}{3} \times \frac{1-D_{0}}{D^{2}\left(D-D_{0}\right)}
\end{gathered}
$$

and, for $D>0.9$ :

$$
\begin{gathered}
G_{1}(D)=\frac{3}{2} \times \frac{D(1-D)}{\left[1-(1-D)^{1 / n}\right]^{n}} \\
G_{2}(D)=\frac{3}{2 n}
\end{gathered}
$$

with: $P$ : applied macroscopic pressure, and $D_{0}$ : green density. To describe the mechanical behavior of the powder particles, equivalent (Von Mises) deformation rate $\dot{\varepsilon}$ and stress $\sigma$ are considered. Then, for a given value of $D$, the plot $\ln \dot{D}=f(\ln \sigma)$ for different values of $P$ at constant $T$ yields a straight line for slope $n$, and the plot $\ln \dot{D}=f\left(\frac{1}{T}\right)$ for different temperatures at constant $P$ gives a straight line for slope $\left(-\frac{Q}{R}\right)$. These calculations require to determine the densification rate, $\dot{D}$. This has been performed by adjusting the densification curves $D(t)$ by polynomials, which were then analytically derived with respect to time. For each densification curve, polynomials of different orders, typically between 3 and 6 were attempted, and the solution best fitting the data was selected. Fig. $5 \mathrm{~b}$ shows two examples of densification curves adjusted by 6th order polynomials. These adjustments had to be carried 
out with care, because the results were highly sensitive to them. Most of the time, adjustments values of $D$ selected for the calculations, for a higher accuracy.

In order to calculate $n$ and $Q$ from equations (4) to (10), it is necessary to make the calculations for identical values of $D$, while keeping unchanged values of geometrical factors $G_{1}(D)$ and $G_{2}(D)$ when changing the applied pressure or temperature. In other words, to achieve identical arrangements of powder particles under each pressure and temperature conditions, and to make calculations independent of the geometrical models describing these arrangements. Thus, Fig. 7a shows $\dot{D}$ evolution for $D$ around 0.82 , for applied pressures between $25 \mathrm{MPa}$ and $75 \mathrm{MPa}$. Fig. 7b shows the plot $\ln \dot{D}-\ln P$ for $D=0.82$, from which $n$ can be calculated. Similarly, $\dot{D}$ has been evaluated around $D=0.75$ between $865^{\circ} \mathrm{C}$ and $969^{\circ} \mathrm{C}$ (plot not shown), and the plot $\ln \dot{D}-\ln 1 / T$ has been drawn (Fig. 8), from which $Q$ can be obtained. These procedures have been performed with the SPS and HP data. The results are summarized in Table 1. As can be seen, the values obtained by SPS and HP are close. This can readily be accounted for by the similarity of the densification kinetics yielded by these two techniques.

With respect to the determination of $n$, another method, based on the variation of the effective pressure on the powder particles with variation of $D$ (Eqs. 6, 8 and 10), had previously been developed $[15,16,27]$. Compared with this approach, our procedure presents the advantage of being independent of the model describing the geometry and the mutual indentation of the powder particles, because the $G_{1}$ and $G_{2}$ functions are constant at a given $D$ value (Eq. (7)-(10)).

\subsection{Analytical calculation of densification curves for different heating rates}


From the activation parameters determined with the SPS isothermal densification curves (Table 1), theoretical anisothermal curves have been calculated and compared with experiments. For this purpose, by numerically integrating over time Eq. 5 with the use of relations (4) and (6)-(10), and by taking for $D_{0}$ the experimental green density $\left(D_{0} \approx 0.61\right.$ 0.63), densification curves for $20^{\circ} \mathrm{C} / \mathrm{min}$ and $100^{\circ} \mathrm{C} / \mathrm{min}$ heating rates have been calculated. To do this, the value of $A_{0}$ of Eq. (4) had to be adjusted and thus, the activation parameters determined for the SPS isothermal densification, $n=1.9$ and $Q=308 \mathrm{~kJ} / \mathrm{mol}$, have been employed. The value of $A_{0}$ has been adjusted to fit the experimental densification curve for $20^{\circ} \mathrm{C} / \mathrm{min}$ and $D<0.9$ (Fig. 9a). This gave: $A_{0}=2 \times 10^{-6} \mathrm{~s}^{-1} \mathrm{~Pa}^{-\mathrm{n}}$. Then, $A_{0}$ and $n$ have been kept constant, and the other curves $\left(20^{\circ} \mathrm{C} / \mathrm{min}-D>0.9,100^{\circ} \mathrm{C} / \mathrm{min}-D<0.9\right.$ and $100^{\circ} \mathrm{C} / \mathrm{min}-$ $D>0.9$, Figs. 9a-b), have been computed, by slightly re-adjusting $Q$ to replicate the data. As can be seen, both portions of the curves $(D<0.9$ and $D>0.9)$ for the two heating rates $\left(20^{\circ} \mathrm{C} / \mathrm{min}\right.$ and $\left.100^{\circ} \mathrm{C} / \mathrm{min}\right)$ are accurately reproduced, for $Q$ varying within the narrow interval $300-315 \mathrm{~kJ} / \mathrm{mol}$. This shows that the densification kinetics in a wide range of heating rates, typical of the SPS experiments, can be reproduced, provided the activation parameters are accurately known.

\section{Discussion}

\subsection{SPS and HP densification kinetics: influence of SPS current}

The first aim of this study was to compare the densification kinetics by SPS and by HP, under identical conditions in terms of sample temperature, heating rate and applied pressure, to decouple the influence of the SPS current on the densification kinetics from the influence of these parameters. Thus, particular care has been taken to achieve identical sample temperatures in both techniques, by calibrating the measured temperature on the melting points of $\mathrm{Al}$ and $\mathrm{Cu}$, and on the $\alpha$ transus of TiAl (Fig. 2). In these conditions, the densification kinetics by SPS and by HP come very close to each other, in isothermal as well 
as in anisothermal experiments (Figs. 4-6). In other words, the electric current flowing

through the samples, which is $\approx 50-100 \mathrm{~A} / \mathrm{cm}^{2}$, does not accelerate significantly the densification kinetics. The microscopic densification mechanism identified in a previous study is plastic deformation of the powder particles kinetically controlled by dislocation climb involving Al bulk diffusion [26]. Therefore, the electric current of the SPS has no detectable influence on these elementary mechanisms. This is contradiction with the studies which assume an impact of the SPS current on diffusion [13] or on plasticity [14]. However, this is in agreement with a previous study, which showed the absence of effect of strong electric current (higher than $1000 \mathrm{~A} / \mathrm{cm}^{2}$ ) on the diffusion kinetics in the Ag-Zn system [33]. This is probably due to the fact that very high current densities (of the order of $10^{6} \mathrm{~A} / \mathrm{cm}^{2}$ ) are needed to exhibit significant "intrinsic" effects (other than Joule effect) on diffusion [34].Then, the typical current density flowing through samples in SPS experiments $\left(\approx 50-100 \mathrm{~A} / \mathrm{cm}^{2}\right)$ is probably not sufficient to accelerate the elementary mechanisms of plasticity and diffusion involved in densification.

\subsection{Stress exponent and activation energy}

The values of stress exponent and activation energy (Table 1) can be compared with literature values obtained for near $\gamma$ TiAl alloys, whose chemistry and microstructure come close to the alloy of this study, and tested in similar conditions of temperature and deformation rate (Table 2). As can be seen, the scattering of the results is very broad. Among these studies, some yield $\dot{\varepsilon}-\sigma$ curves. They are reported in Figs. 10a and b which also plot deformation kinetics calculated with the activation parameters of the SPS and HP experiments: $Q=308 \mathrm{~kJ} / \mathrm{mol}, n=1.9, A_{0}=2 \times 10^{-6} \mathrm{~s}^{-1} \mathrm{~Pa}^{-\mathrm{n}}$ for SPS, $Q=276 \mathrm{~kJ} / \mathrm{mol}, n=1.5, A_{0}$ $=1.5 \times 10^{-4} \mathrm{~s}^{-1} \mathrm{~Pa}^{-\mathrm{n}}$ for HP (in the case of HP, the value of $A_{0}$ furnishing the best agreement with the literature data has been retained). Clearly, our results lie within the cloud of data found in the literature, which extends, for given temperature, $\dot{\varepsilon}$ and $\sigma$ conditions, over up to 
one order of magnitude. This spreading probably originates from a very high sensitivity of the data from the HP experiments (Fig. 10b), the agreement is somehow less satisfactory than with the SPS experiment data (Fig. 10a). This is due to the curve slopes, that is, to the $n$ values. It is then likely that the best value of $n$ is around 2, and that the value obtained with the HP experiments $(n=1.5 \pm 0.3)$ is slightly underestimated.

The values of activation parameters $n$ and $Q$ give a hint at the densification mechanisms, following the sintering theories $[35,36]$. The low value of $n$, around 2 , suggests that kinetics is controlled by diffusion. Moreover, the activation energy measured, $300 \mathrm{~kJ} / \mathrm{mol}$, is not far from the value for diffusion of $\mathrm{Al}$ in $\mathrm{TiAl}, 360 \mathrm{~kJ} / \mathrm{mol}$ [37]. Diffusion of $\mathrm{Al}$ then appears as a probable mechanism for densification. Microstructural characterizations showed that densification of TiAl by SPS occurs by deformation at the necks between the powder particles $[20,26]$. This could result from different mechanisms: dislocation glide and climb, volume diffusion (Nabarro-Herring mechanism), grain boundary diffusion (Coble mechanism) and grain boundary sliding. Accurate TEM observations evidenced twinning, glide and climb mechanisms in the neck regions, the kinetics being probably controlled by glide and twinning in the high effective stress - low temperature regime of the beginning of densification, then by climb in the low effective stress - high temperature regime of the end of densification [26]. The analyses of this study suggest that, by being part of the dislocation climb, Al diffusion controls the densification during most of the SPS cycle, dislocation glide and twinning being active only at the very beginning of the cycle, when the contact areas between the powder particles are almost restricted to points, leading to very high local stress. In summary, both the macroscopic and microscopic studies point to a dislocation climb controlled by $\mathrm{Al}$ diffusion as the mechanism controlling the densification kinetics during the SPS and HP experiments.

\subsection{Theoretical calculation of densification curves}


In this study, the apparent activation parameters $n$ and $Q$ have been determined in isothermal experiments (Figs. 7, 8), and used to compute the theoretical anisothermal densification curves at $20^{\circ} \mathrm{C} / \mathrm{min}$ and $100^{\circ} \mathrm{C} / \mathrm{min}$ (Fig. 9). It can be seen in Fig. 9 that, once $A_{0}$ is adjusted, the anisothermal densification curves can be accurately calculated, with only a minor adjustment of the value of $Q$. This shows, in an alternative way, that the densification mechanisms, under a fast heating rate of the SPS, involve classical metallurgical mechanisms. Consequently, the rapidity of the SPS reflects the high heating rate of the powder, without intrinsic current effect.

The determination of the $A_{0}, n$ and $Q$ parameters of the powder provides a valuable method for estimating the densification kinetics by SPS. This method could probably be implemented with a high degree of accuracy to estimate the densification kinetics of more complex parts, providing the related temperature, stress and strain fields could be described by appropriate models. However, it can be seen from Fig. 9 that, because the value of the activation energy greatly impacts the densification kinetics, its value has to be very accurately determined.

\section{Conclusions}

To evaluate the role of the SPS current $\left(\approx 50-100 \mathrm{~A} / \mathrm{cm}^{2}\right)$ on the densification kinetics, comparisons have been made with the current-free HP technique, with proper calibration of the sample temperature in both cases. Isothermal and anisothermal experiments show that the SPS and HP kinetics exhibit no significant differences. Consequently, the stress exponent $(n)$ and activation energy $(Q)$ are close in both techniques: $n=1.9 \pm 0.3$ and $Q=308 \pm 20 \mathrm{~kJ} / \mathrm{mol}$ for SPS, $n=1.5 \pm 0.3$ and $Q=276 \pm 40 \mathrm{~kJ} / \mathrm{mol}$ for HP. With these data, and with preexponential value $A_{0}=2 \times 10^{-6} \mathrm{~s}^{-1} \mathrm{~Pa}^{-\mathrm{n}}$, anisothermal SPS densification kinetics using typical heating rates $\left(20^{\circ} \mathrm{C} / \mathrm{min}\right.$ and $\left.100^{\circ} \mathrm{C} / \mathrm{min}\right)$ have been accurately reproduced analytically. These activation parameters are in agreement with those determined in the literature on bulk TiAl 
samples. They suggest that densification of TiAl by SPS and HP is mostly controlled by Al bulk diffusion, through its involvement in dislocation climb, the mechanisms of dislocation glide and twinning being active only in the small interparticle regions at the very beginning of the densification cycle. In summary, the SPS densification mechanisms involve classical metallurgical mechanisms, without intrinsic contribution of the current.

\section{Acknowledgements}

This work has been financially supported by a grant within the framework of the MF2ANR-2011-PBS09-020 project of the French Agence Nationale de la Recherche. SPS studies have been performed with the Sumitomo 2080 SPS machine of the Plateforme Nationale de Frittage Flash du CNRS (PNF2-CNRS, Paul Sabatier University, Toulouse, France).

\section{References}

[1] Z. Shen, M. Johnson, Z. Zhao, M. Nygren, Spark plasma sintering of alumina, Journal of the American Ceramic Society 85 (2002) 1921-1927.

[2] G. Jouan, M. Dollé, J.P. Monchoux, Decoupling the effects of pressure and current in spark plasma sintering: synthesis of Cu0.9V2O5, Solid State Ionics 236 (2013) 5-10.

[3] M. Tokita, Development of large-size ceramic/metal bulk FGM fabricated by spark plasma sintering, Materials Science Forum 308-311 (1999) 83-88.

[4] M. Omori, Sintering, consolidation, reaction and crystal growth by the spark plasma system (SPS), Materials Science and Engineering A287 (2000) 183-188.

[5] O. Yanagisawa, H. Kuramoto, K. Matsugi, Komatsu, Observation of particle behavior in copper powder compact during pulsed electric discharge, Materials Science and Engineering A350 (2003) 184-189. 
[6] T. Saunders, S. Grasso, M.J. Reece, Plasma formation during electric discharge (50 V) through conductive powder compacts, Journal of the European Ceramic Society 35 (2015) 871-877.

[7] R. Marder, C. Estournès, G. Chevallier, R. Chaim, Plasma in spark plasma sintering of ceramic particle compacts, Scripta Materialia 82 (2014) 57-60.

[8] R. Marder, C. Estournès, G. Chevallier, R. Chaim, Spark and plasma in spark plasma sintering of rigid ceramic nanoparticles: A model system of YAG, Journal of the European Ceramic Society 35 (2015) 211-218.

[9] R. Chaim. Electric field effects during spark plasma sintering of ceramic nanoparticles, Journal of Materials Science 48 (2013) 502-510.

[10] R. Marder, C. Estournès, G. Chevallier, R. Chaim, Numerical model for sparking and plasma formation during spark plasma sintering of ceramic compacts, Journal of Materials Science 50 (2015) 4636-4645.

[11] T. Grosdidier, G. Ji, F. Bernard, E. Gaffet, Z.A. Munir, S. Launois, Synthesis of bulk FeAl nanostructured materials by HVOF spray forming and spark plasma sintering, Intermetallics 14 (2006) 1208-1213.

[12] G. Ji, T. Grosdidier, N. Bozzolo, S. Launois, The mechanisms of microstructure formation in a nanostructured oxide dispersion strengthened FeAl alloy obtained by spark plasma sintering, Intermetallics 15 (2007) 108-118.

[13] Z.A. Munir, U. Anselmi-Tamburini, M. Ohyanagi, The effect of electric field and pressure on the synthesis and consolidation of materials : a review of the spark plasma sintering method, Journal of Materials Science 41 (2006) 763-777.

[14] H. Conrad. Electroplasticity in metals and ceramics. Materials Science and Engineering A287 (2000) 276-287. 
[15] G. Bernard-Granger, A. Addad, G. Fantozzi, G. Bonnefont, C. Guizard, D. Vernat. Spark plasma sintering of a commercially avaiblable granulated zirconia powder: comparison with hot-pressing. Acta Materialia 58 (2010) 3390-3399.

[16]. L. Ramond, G. Bernard-Granger, A. Addad, C. Guizard. Sintering of a quasi-crystalline powder using spark plasma sintering and hot pressing. Acta Materialia 58 (2010) 5120-5128.

[17] R. Collet, S. Le Gallet, F. Naimi, F. Charlot, S. Lay, G. Bonnefont, G. Fantozzi, J.-M. Chaix, F. Bernard. Current effect on the sintering by SPS of a pre-oxidized copper powder. Journal of Alloys and Compounds, 692 (2017) 478-484.

[18] T. Voisin, J.P. Monchoux, L. Durand, N. Karnatak, M. Thomas, A. Couret. An innovative way to produce $\gamma$-TiAl blades: spark plasma sintering. Advanced Engineering Materials 17 (2015) 1408-1413.

[19] A. Couret, G. Molénat, J. Galy, M. Thomas, Microstructures and mechanical properties of TiAl alloys consolidated by spark plasma sintering, Intermetallics 16 (2008) 1134-1141.

[20] H. Jabbar, A. Couret, L. Durand, J.P. Monchoux. Identification of microstructural mechanisms during densification of a TiAl alloy by spark plasma sintering. Journal of Alloys and Compounds 509 (2011) 9826-9835.

[21] H. Jabbar, J.P. Monchoux, M. Thomas, A. Couret. Microstructure and deformation mechanisms of a G4 TiAl alloy produced by spark plasma sintering. Acta Materialia 59 (2011) 7574-7585.

[22] H. Jabbar, J.P. Monchoux, M. Thomas, F. Pyczak, A. Couret, Improvement of the creep properties of TiAl alloys densified by spark plasma sintering, Intermetallics 46 (2014) 1-3.

[23] T. Voisin, J.P. Monchoux, M. Hantcherli, S. Mayer, H. Clemens, A. Couret. Acta Materialia 73 (2014) 107-115. 
[24] M. Charpentier. PhD Thesis, Institut National Polytechnique de Lorraine, Nancy, 2003.

[25] J. Guyon, A. Hazotte, E. Bouzy. Evolution of metastable $\alpha$ phase during heating of Ti48Al2Cr2Nb intermetallic alloy. Journal of Alloys and Compounds 656 (2016) 667-675.

[26] Z. Trzaska, A. Couret, J.P. Monchoux. Spark plasma sintering mechanisms at the necks between TiAl powder particles. Acta Materialia 118 (2016) 100-108.

[27] G. Bernard-Granger, C. Guizard. Spark plasma sintering of a commercially available granulated ziconia powder: I. Sintering path and hypotheses about the mechanism(s) controlling densification. Acta Materialia 55 (2007) 3493-3504.

[28] T. Voisin, L. Durand, N. Karnatak, S. Le Gallet, M. Thomas, Y. Le Berre, J.F. Castagné, A. Couret. Temperature control during Spark Plasma Sintering and application to up-scaling and complex shaping. Journal of Materials Processing Technology 213 (2013) 269-278.

[29] A. Pavia, L. Durand, F. Ajustron, V. Bley, G. Chevallier, A. Peigney, C. Estournès, Electro-thermal measurements and finite element method simulations of a spark plasma sintering device, Journal of Materials Processing Technology 213 (2013) 1327-1336.

[30] T. Misawa, N. Shikatani, Y. Kawakami, T. Enjoji, Y. Ohtsu, H. Fujita. Observation of internal pulsed current flow through the $\mathrm{ZnO}$ specimen in the spark plasma sintering method. Journal of Materials Science 44 (2009) 1641-1651.

[31] E. Arzt, M.F. Ashby, K.E. Easterling. Practical applications of hot-isostatic pressing diagrams: four case studies. Metallurgical Transactions A 14 (1983) 211-221.

[32] A.S. Helle, K.E. Easterling, M.F. Ashby. Hot-isostatic pressing diagrams: new developments. Acta Metallurgica 33 (1985) 2163-2174.

[33] Z. Trzaska, J.P. Monchoux. Electromigration experiments by spark plasma sintering in the silver-zinc system. Journal of Alloys and Compounds 635 (2015) 142-149. 
[34] R. Frankovic. Electromigration drift and threshold in $\mathrm{Cu}$ thin-film interconnects. IEEE Transactions on Electron Devices 43 (1996) 2233-2239.

[35] D. Bernache-Assolant. "Chimie-physique du frittage”. Hermès, Paris, 1993.

[36] M.N. Rahaman. "Ceramic processing and sintering." Taylor and Francis, Boca Raton, 2003.

[37] C. Herzig, T. Przeorski, Y. Mishin. Self-diffusion in gamma-TiAl: an experimental study and atomistic calculations. Intermetallics 7 (1999) 389-404.

[38] S.C. Cheng, J. Wolfenstine, O.D. Sherby. Superplastic behavior of 2-phase titanium aluminides. Metallurgical Transactions A 23 (1992) 1509-1513.

[39] R.M. Imayev, G.A. Salishchev, O.N. Senkov, V.M. Imayev, M.R. Shagiev, N.K. Gabdullin, A.V. Kuznetsov, F.H. Froes. Low-temperature superplasticity of titanium aluminides. Materials Science and Engineering A300 (2001) 263-277.

[40] T.G. Nieh, L.M. Hsiung, J. Wadsworth. Superplastic behavior of a powder metallurgy TiAl alloy with a metastable microstructure. Intermetallics 7 (1999) 163-170.

[41] L.M. Hsiung, T.G. Nieh. Microstructures and properties of powder metallurgy TiAl alloys. Materials Science and Engineering A 364 (2004) 1-10.

[42] D. Lin, F. Sun. Superplasticity in a large-grained TiAl alloy. Intermetallics 12 (2004) $875-883$.

[43] J. Sun, J.S. Wu ; Y.H. He. J. Superplastic properties of a TiAl based alloy with a duplex microstructure. Materials Science 35 (2000) 4919-4922.

[44] R.K. Gupta, S.V.S. Narayana Murty, Bhanu Pant, Vijaya Agarwala, P.P. Sinha. Hot workability of $\gamma+\alpha_{2}$ titanium aluminide: Development of processing map and constitutive equations. Materials Science and Engineering A 551 (2012) 169-186. 
[45] V.M. Imayev, G.A. Salshchev, M.R. Shagiev, A.V. Kuznetsov, R.M. Imayev, O.N. Senkov and F.H. Froes. Low temperature superplasticity of submicrocrystalline Ti-48Al-2Nb2Cr. Scripta Materialia 40 (1999) 183-190.

[46] J. Sun, Y.H. He, J.S. Wu. Characterization of low-temperature superplasticity in a thermomechanically processed TiAl based alloy. Materials Science and Engineering A329331 (2002) 885-890. 


\section{Tables}

Table 1. $n$ and $Q$ values obtained.

\begin{tabular}{|c|c|c|}
\hline & HP & SPS \\
\hline$n$ & $1.5 \pm 0.3$ & $1.9 \pm 0.3$ \\
\hline$Q(\mathrm{~kJ} / \mathrm{mol})$ & $276 \pm 40$ & $308 \pm 20$ \\
\hline
\end{tabular}

Table 2. Bibliographic review of the $n$ and $Q$ values.

\begin{tabular}{|c|c|c|c|c|c|c|}
\hline Alloy & Microstructure & $\mathrm{T}\left({ }^{\circ} \mathrm{C}\right)$ & $\dot{\varepsilon}\left(\mathrm{s}^{-1}\right)$ & $n$ & $\begin{array}{c}Q \\
(\mathrm{~kJ} / \mathrm{mol})\end{array}$ & Ref. \\
\hline $\mathrm{Ti}_{57} \mathrm{Al}_{43}$ & $52 \% \gamma+48 \% \alpha_{2}$ & $1000-1100$ & $10^{-5}-10^{-2}$ & $2-4$ & 390 & {$[38]$} \\
\hline $\mathrm{Ti}_{48} \mathrm{Al}_{48} \mathrm{Cr}_{2} \mathrm{Nb}_{2}$ & $\gamma+10-15 \% \alpha_{2}$ & $\begin{array}{c}600-1050 \\
800\end{array}$ & $\begin{array}{c}10^{-4}-10^{-1} \\
10^{-4}-10^{-3}\end{array}$ & $\begin{array}{c}1.7-4.2 \\
1.7-2.2\end{array}$ & 200 & {$[39]$} \\
\hline $\mathrm{Ti}_{49} \mathrm{Al}_{47} \mathrm{Cr}_{2} \mathrm{Nb}_{1} \mathrm{Ta}_{1}$ & $50 \%\left(\gamma+\alpha_{2}\right)+50 \% \mathrm{~B} 2$ & $800-1000$ & $10^{-6}-10^{-4}$ & 2 & 210 & {$[40,41]$} \\
\hline $\mathrm{Ti}_{48} \mathrm{Al}_{47} \mathrm{Mn}_{2} \mathrm{Nb}_{2} \mathrm{~B}_{1}$ & Near $\gamma$ & & & 2.6 & & {$[42]$} \\
\hline $\mathrm{Ti}_{50.8} \mathrm{Al}_{46.8} \mathrm{Cr}_{2.2} \mathrm{Mo}_{0.2}$ & Duplex & & & 2.5 & 345 & {$[43]$} \\
\hline $\mathrm{Ti}_{48} \mathrm{Al}_{48} \mathrm{Cr}_{2} \mathrm{Nb}_{2}$ & $\gamma+\alpha_{2}$ & $950-1150$ & $10^{-3}-10^{-1}$ & $2.8-8$ & 335 & {$[44]$} \\
\hline $\mathrm{Ti}_{53} \mathrm{Al}_{47}$ & $\gamma+\alpha_{2}$ & $600-900$ & $10^{-8}-10^{-7}$ & 2.3 & 340 & {$[38]$} \\
\hline $\mathrm{Ti}_{48} \mathrm{Al}_{48} \mathrm{Cr}_{2} \mathrm{Nb}_{2}$ & $\gamma+10-15 \% \alpha_{2}$ & $750-850$ & $2 \times 10^{-4}$ & 1.7 & 194 & {$[45]$} \\
\hline $\mathrm{Ti}_{50.8} \mathrm{Al}_{46.8} \mathrm{Cr}_{2.2} \mathrm{Mo}_{0.2}$ & $\gamma+\alpha_{2}$ & $800-900$ & $2 \times 10^{-5}-2 \times 10^{-4}$ & $1.7-2.8$ & 220 & {$[46]$} \\
\hline
\end{tabular}




\section{Figure captions}

Fig. 1. (a) Punch displacement $d$ as a function of pyrometer temperature $T_{\text {Pyro }}$ during an experiment of melting of $\mathrm{Cu}$ (melting temperature: $1085^{\circ} \mathrm{C}$ ) by SPS. When $\mathrm{Cu}$ melts, at $T_{\text {pyro }}=1058^{\circ} \mathrm{C}$, the punch displacement accelerates sharply (arrow). TiAl $\gamma+$ lamellar (b), and fully lamellar (c) microstructures in HP experiments interrupted at pyrometer temperatures of $1350^{\circ} \mathrm{C}$ (b) and $1375^{\circ} \mathrm{C}$ (c). The pyrometer temperature for $\alpha$ transus is then: $\mathrm{T}_{\mathrm{pyro}}(\alpha)=1362.5 \pm 12.5^{\circ} \mathrm{C}$

Fig. 2. Calibration curves of sample temperature $\left(\mathrm{T}_{\text {sample }}\right)$ as a function of measured temperature by external pyrometer $\left(\mathrm{T}_{\text {pyro }}\right)$ in SPS and HP experiments, for melting of Al $\left(660^{\circ} \mathrm{C}\right), \mathrm{Cu}\left(1085^{\circ} \mathrm{C}\right)$ and for the $\mathrm{TiAl} \alpha$ transus $\left(1335^{\circ} \mathrm{C}\right)$.

Fig. 3. Recordings of $T_{\mathrm{pyro}}, P, d_{\mathrm{p}}$ and $d_{\mathrm{b}}$ for SPS (a) and HP (b) cycles, in experiments of isothermal densification during $60 \mathrm{~min}$ at $T_{\text {sample }}=969^{\circ} \mathrm{C}\left(\right.$ corresponding to $T_{\mathrm{pyro}}(\mathrm{SPS})=$ $950^{\circ} \mathrm{C}$, and $T_{\mathrm{pyro}}(\mathrm{HP})=1023^{\circ} \mathrm{C}$ ). Time origin is taken at the beginning of the isothermal plateau. (c) Recordings of $U$ and $I$ in the case of the SPS experiment, and plot of $J$, considering that $30 \%$ of the SPS current flows through the sample.

Fig. 4. Isothermal densification curves at different temperatures $(P=50 \mathrm{MPa})$.

Fig. 5. Isothermal densification curves. (a) $P=33 \mathrm{MPa}$. (b) $P=75 \mathrm{MPa}\left(T_{\text {sample }}=969^{\circ} \mathrm{C}\right)$. Examples of 6th order polynomial fits (see text) are shown as dotted curves.

Fig. 6. (a) $P$ and $T_{\text {sample }}$ profiles in the SPS and HP experiments, and $J$ profile (considering that $30 \%$ of the current flows through the sample) in the SPS experiments. (b) Densification curves at $20^{\circ} \mathrm{C} / \mathrm{min}$ by SPS and HP.

Fig. 7. Analysis of the isothermal densification curves under different applied stresses ( $T_{\text {sample }}=969^{\circ} \mathrm{C}$ ). (a) $\dot{D}-D$ curves around $D=0.82$. (b) $\ln \dot{D}-\ln P$ curves for $D=0.82$. 
Fig. 8. $\ln (\dot{D})-1 / T$ plot for $\dot{D}$ evaluated around $D=0.75(\mathrm{P}=50 \mathrm{MPa})$, for $T$ between $865^{\circ} \mathrm{C}$ and $969^{\circ} \mathrm{C}$.

Fig. 9. Analytical calculations of the SPS densification curves, for $\mathrm{A}_{0}$ adjusted to $2 \times 10^{-6} \mathrm{~s}^{-1} \mathrm{~Pa}^{-}$ ${ }^{\mathrm{n}}, \mathrm{n}=1.9$ and Q between $300 \mathrm{~kJ} / \mathrm{mol}$ and $315 \mathrm{~kJ} / \mathrm{mol}$. (a) $20^{\circ} \mathrm{C} / \mathrm{min}$. (b) $100^{\circ} \mathrm{C} / \mathrm{min}$.

Fig. 10. Norton laws of the TiAl of this study, drawn with the activation parameters determined with the SPS (a) and HP (b) densification experiments. Data available from the literature are also indicated, for comparison purposes. 
Click here to download high resolution image
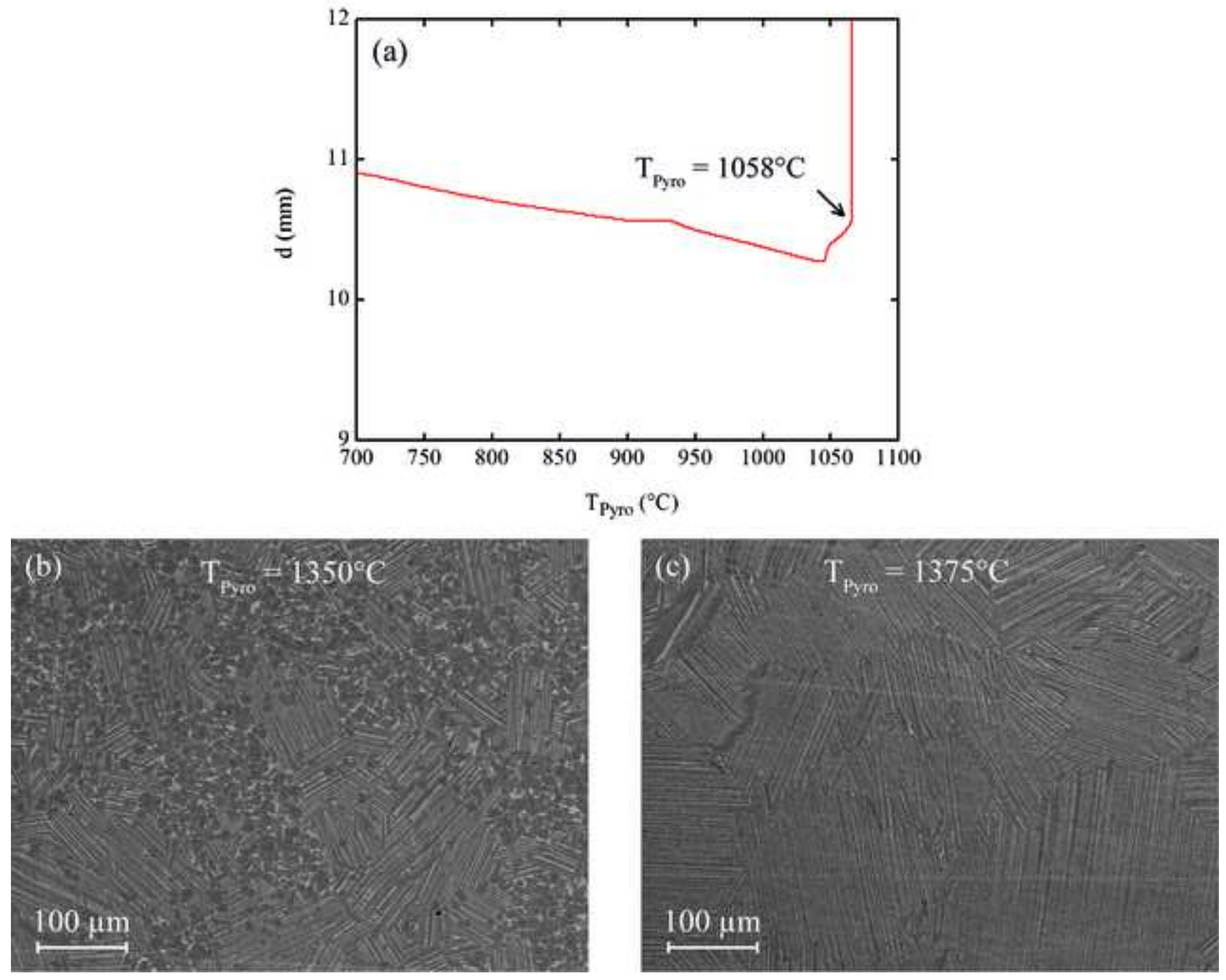


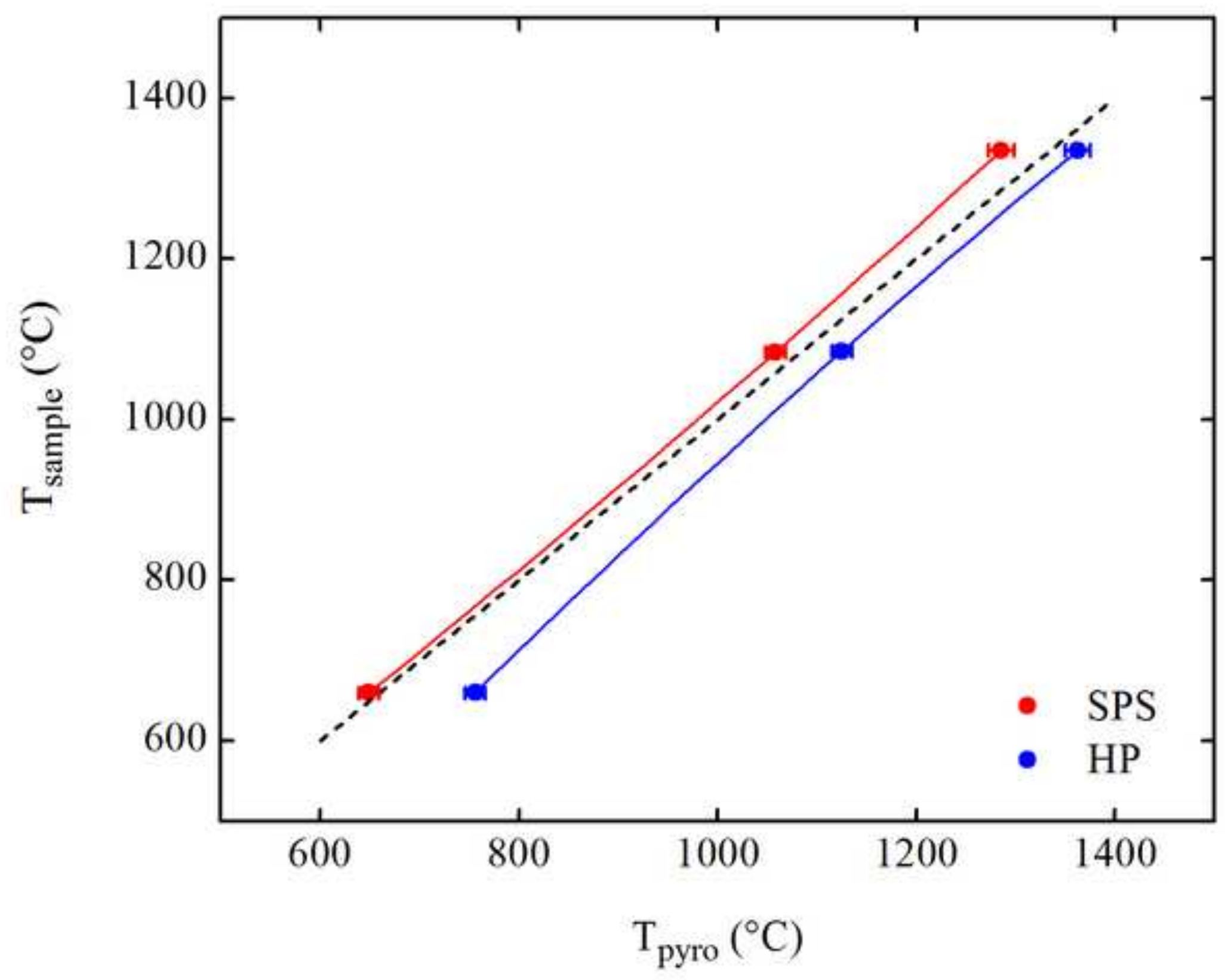



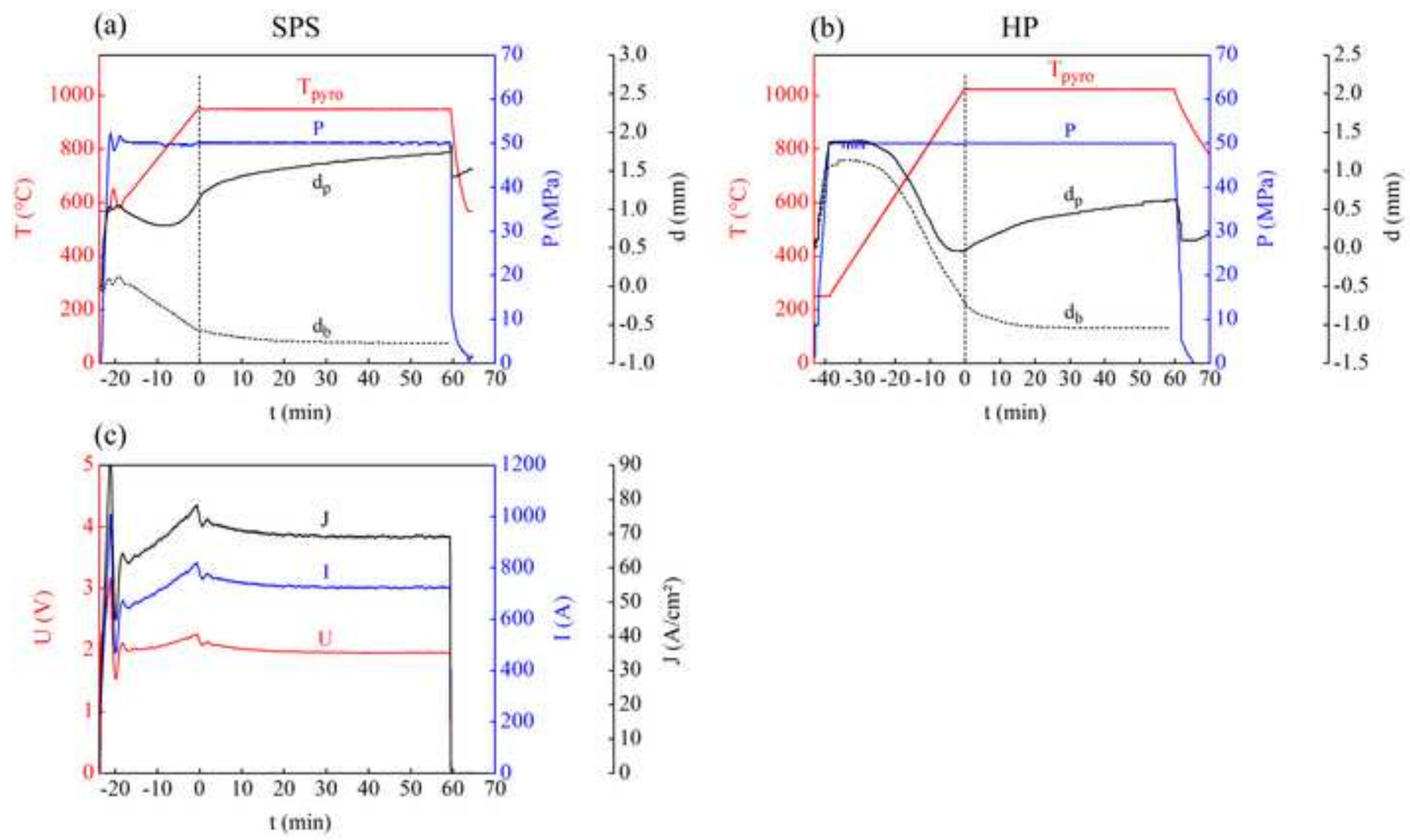
Click here to download high resolution image
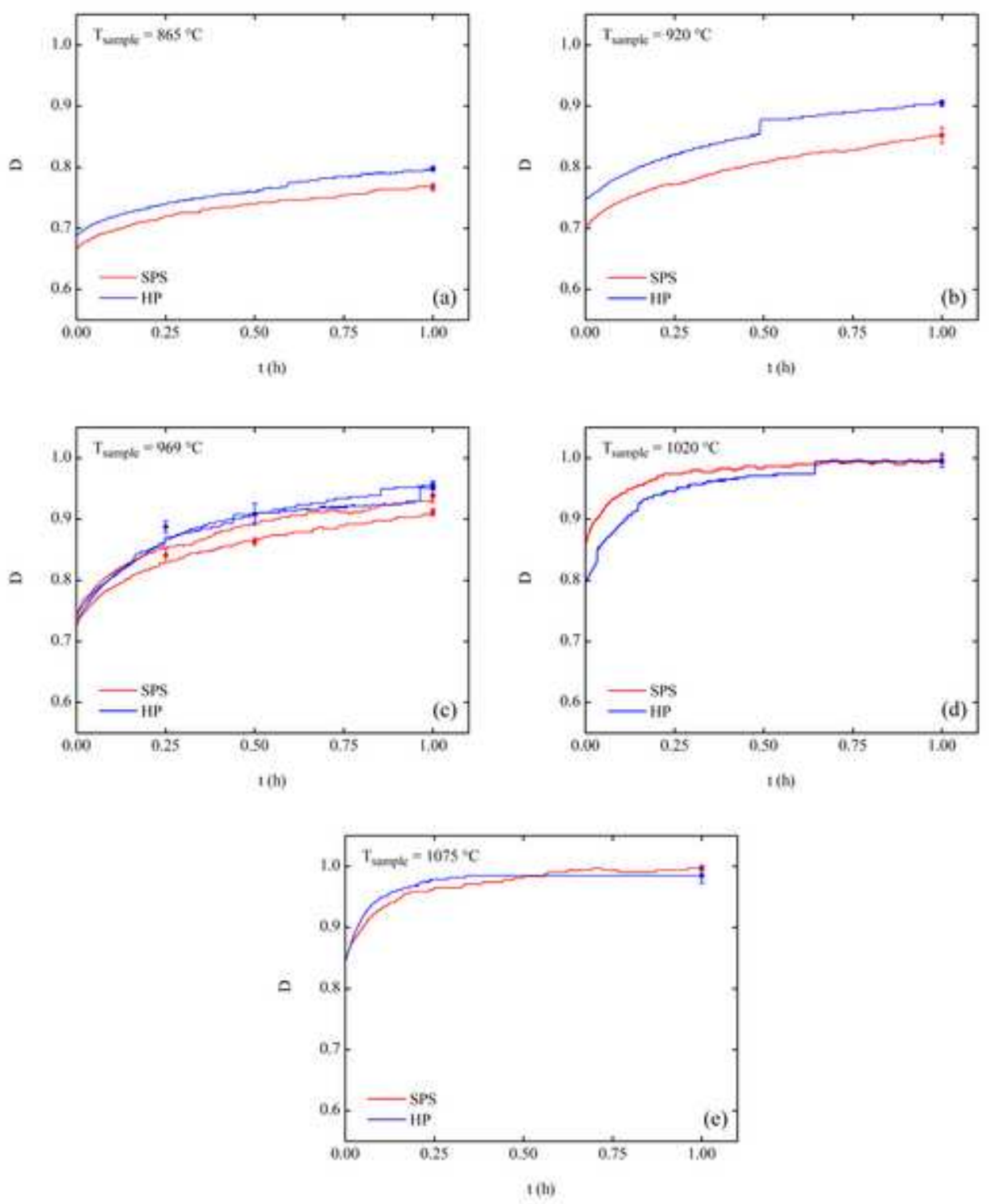
Click here to download high resolution image
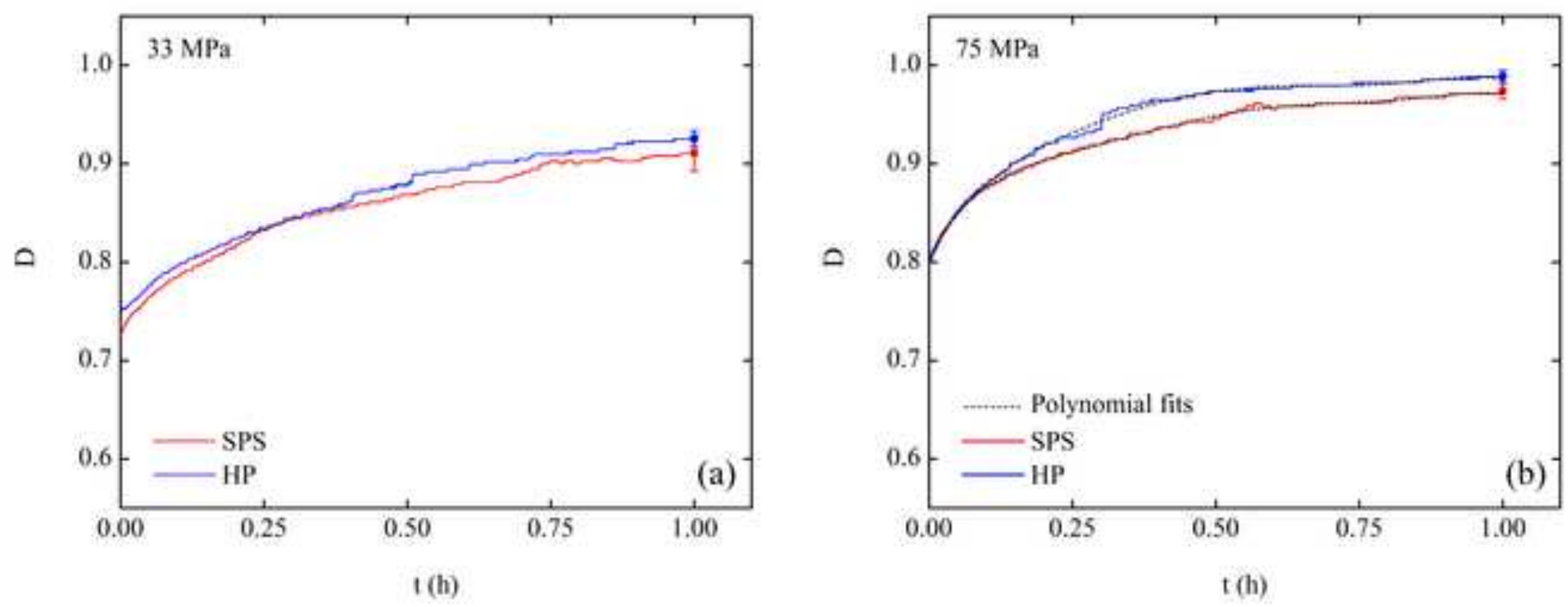
Click here to download high resolution image
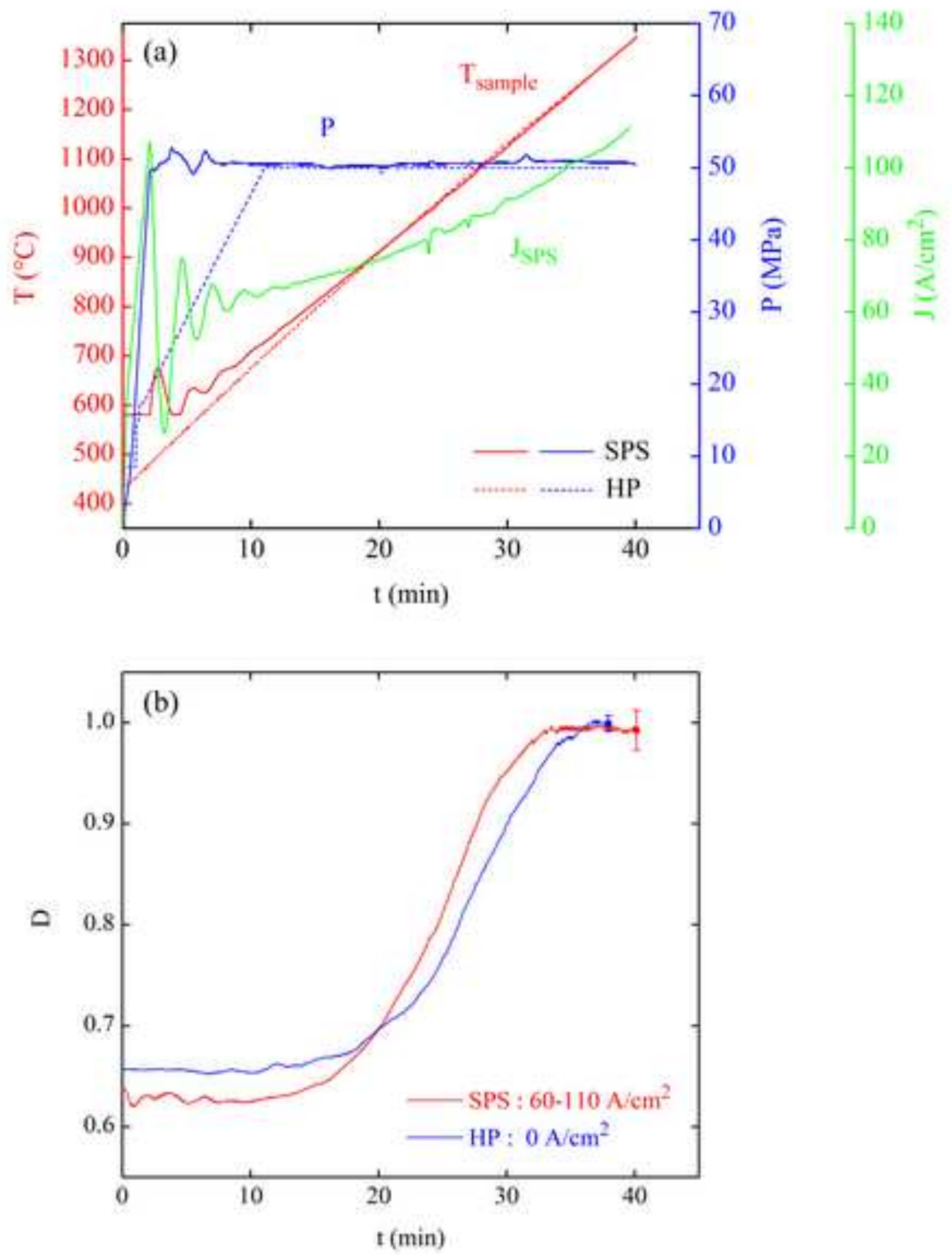


\section{Fig. 7}

Click here to download high resolution image

(a)

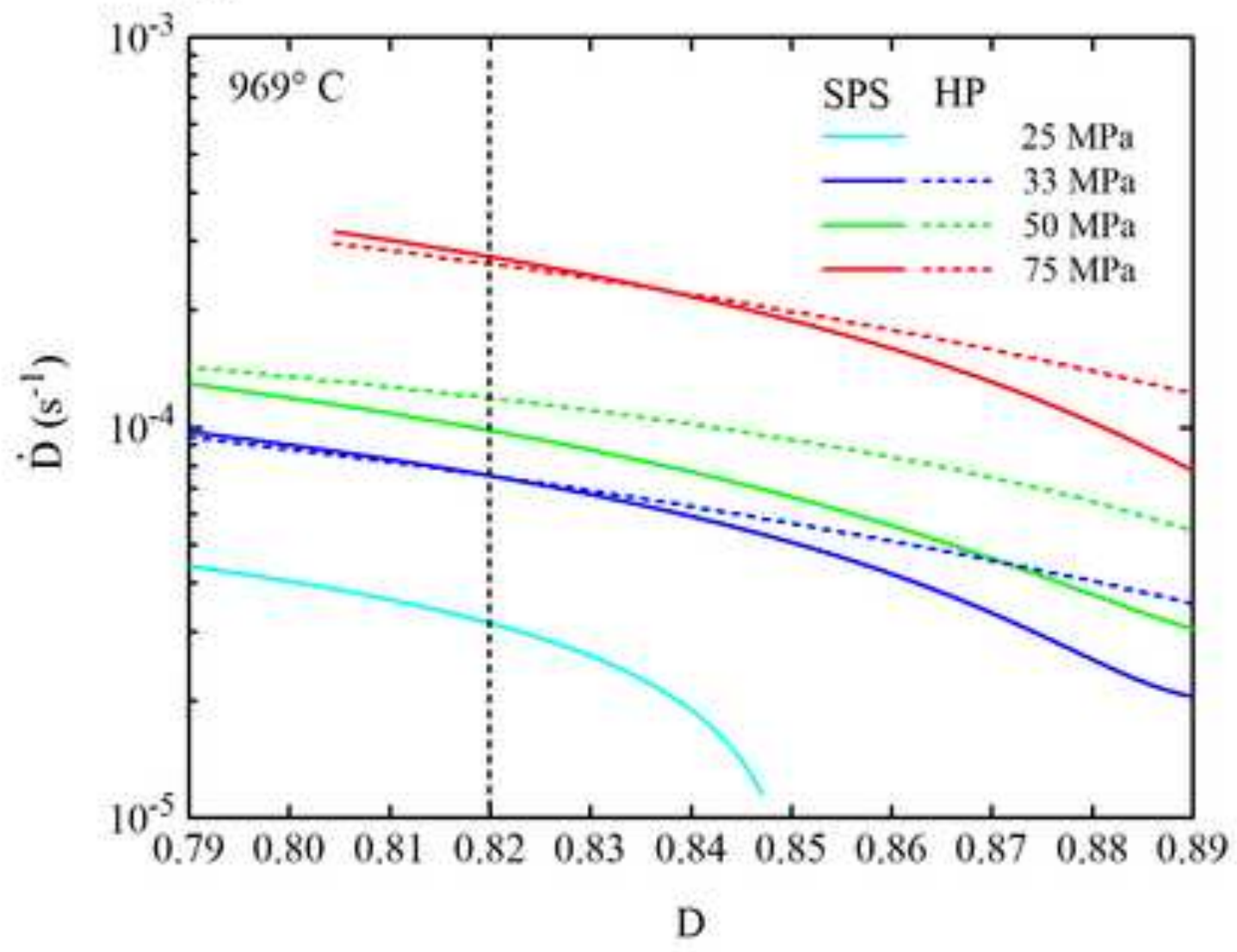

(b)

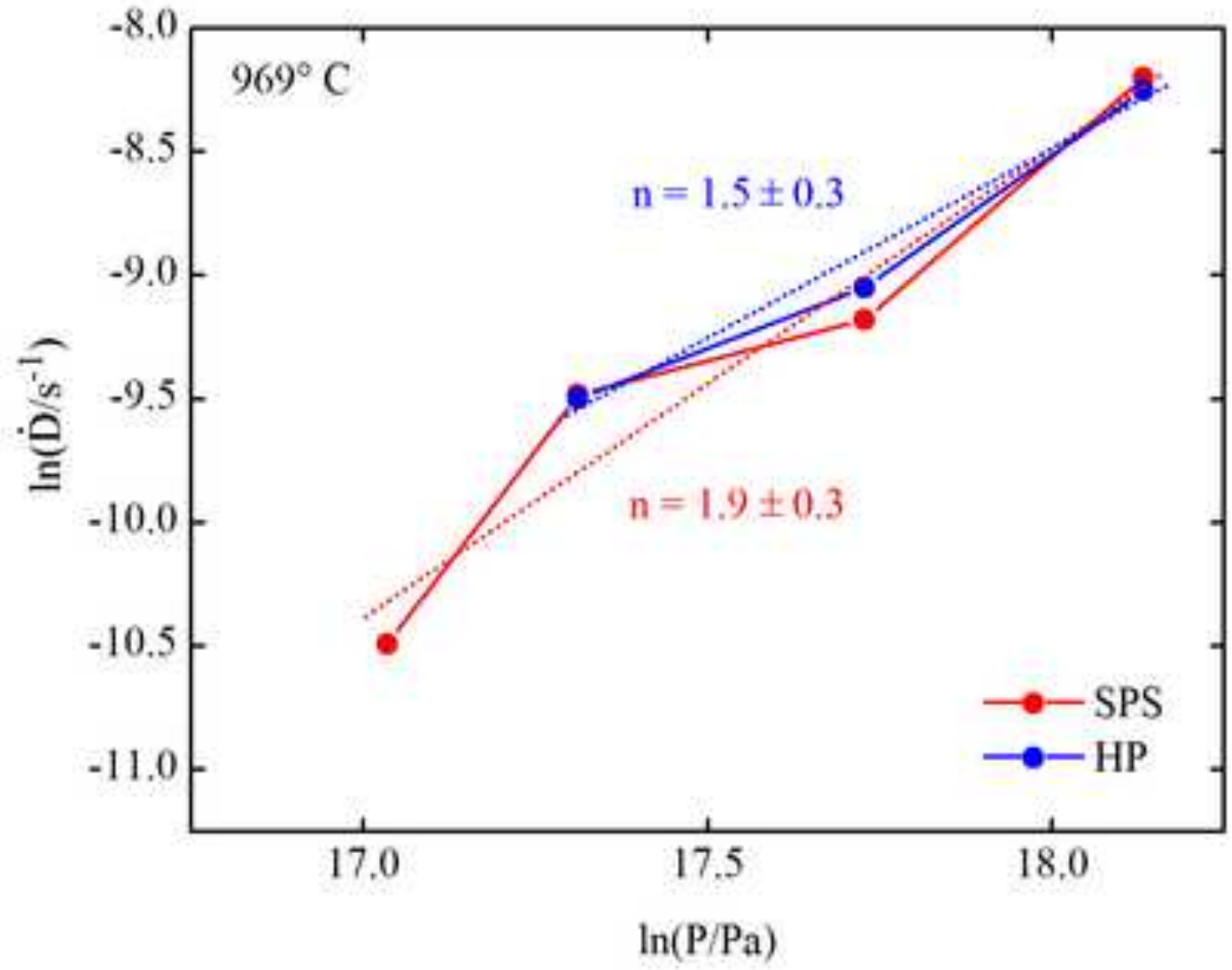


$\mathrm{T}\left({ }^{\circ} \mathrm{C}\right)$

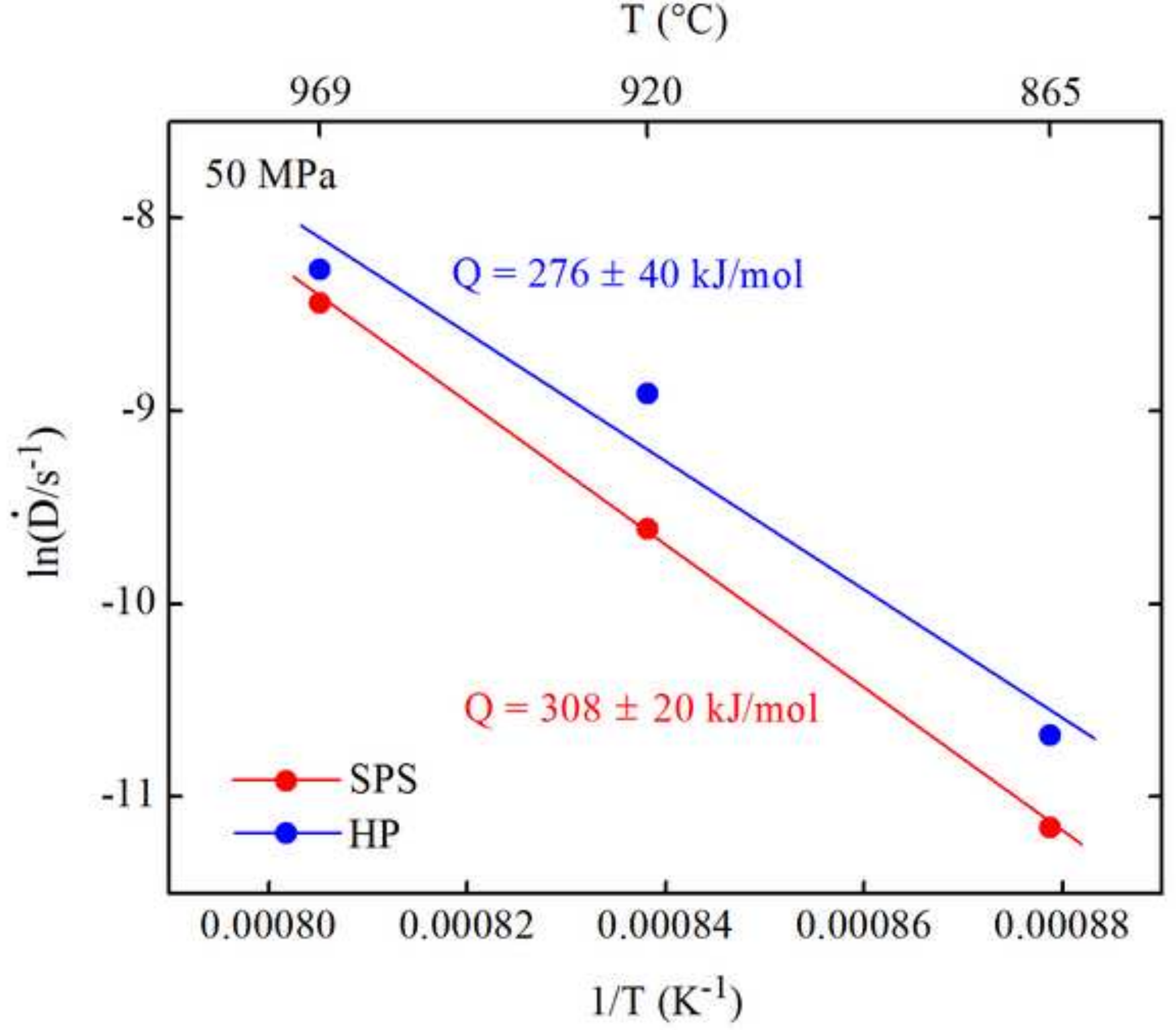


Fig. 9

Click here to download high resolution image

(a)
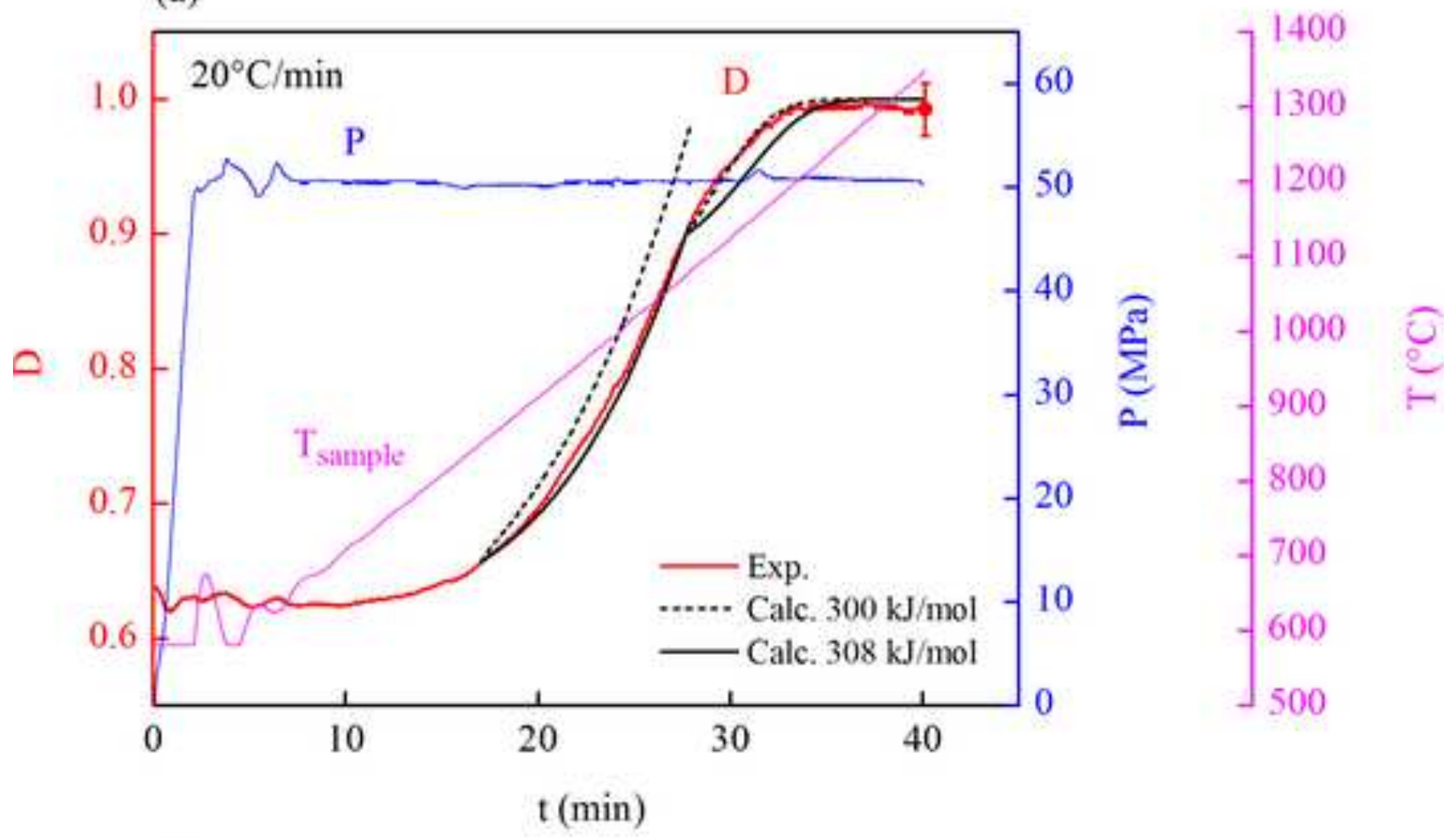

(b)
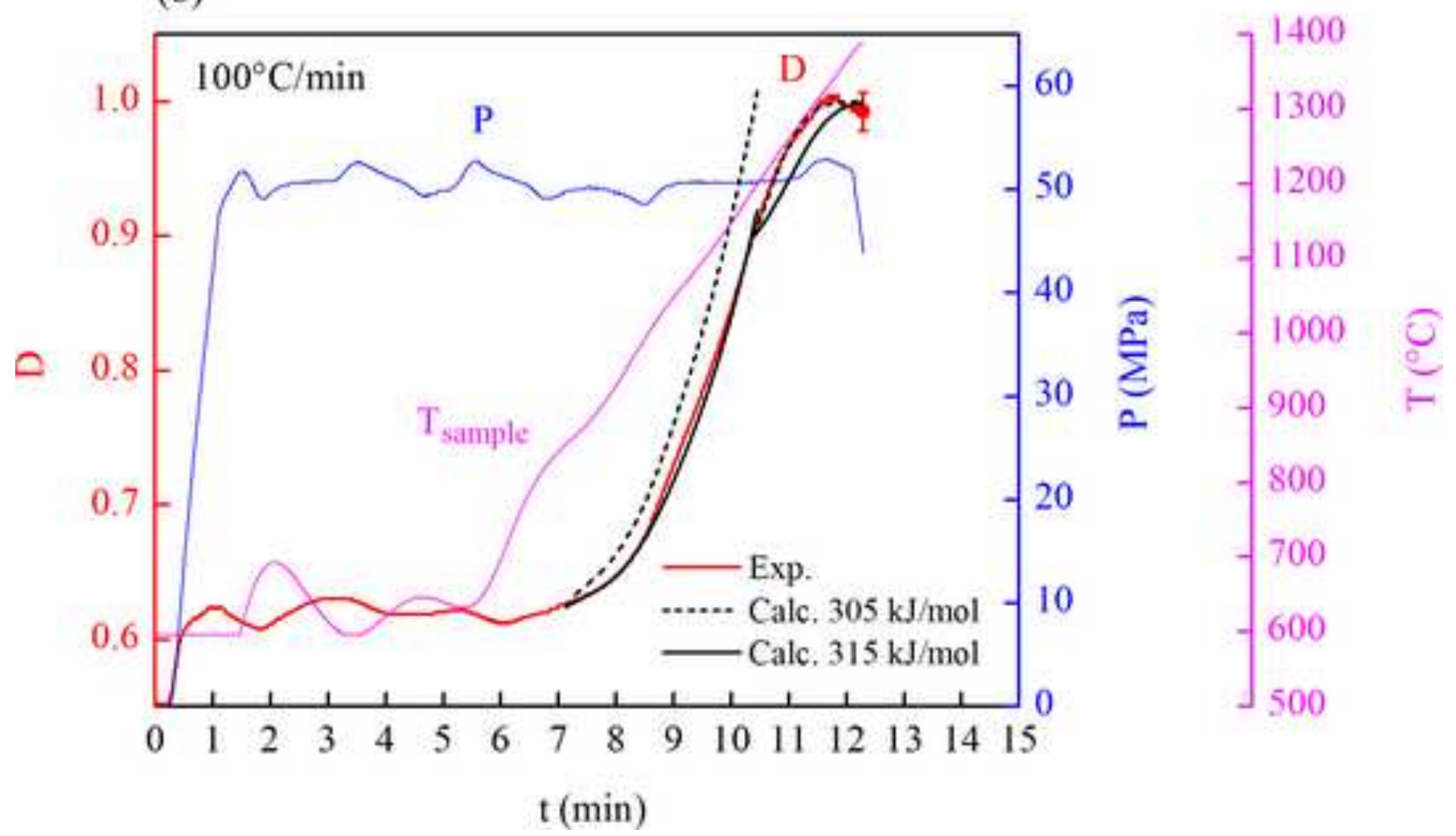

$\mathrm{t}$ (min) 
Fig. 10

Click here to download high resolution image

(a)

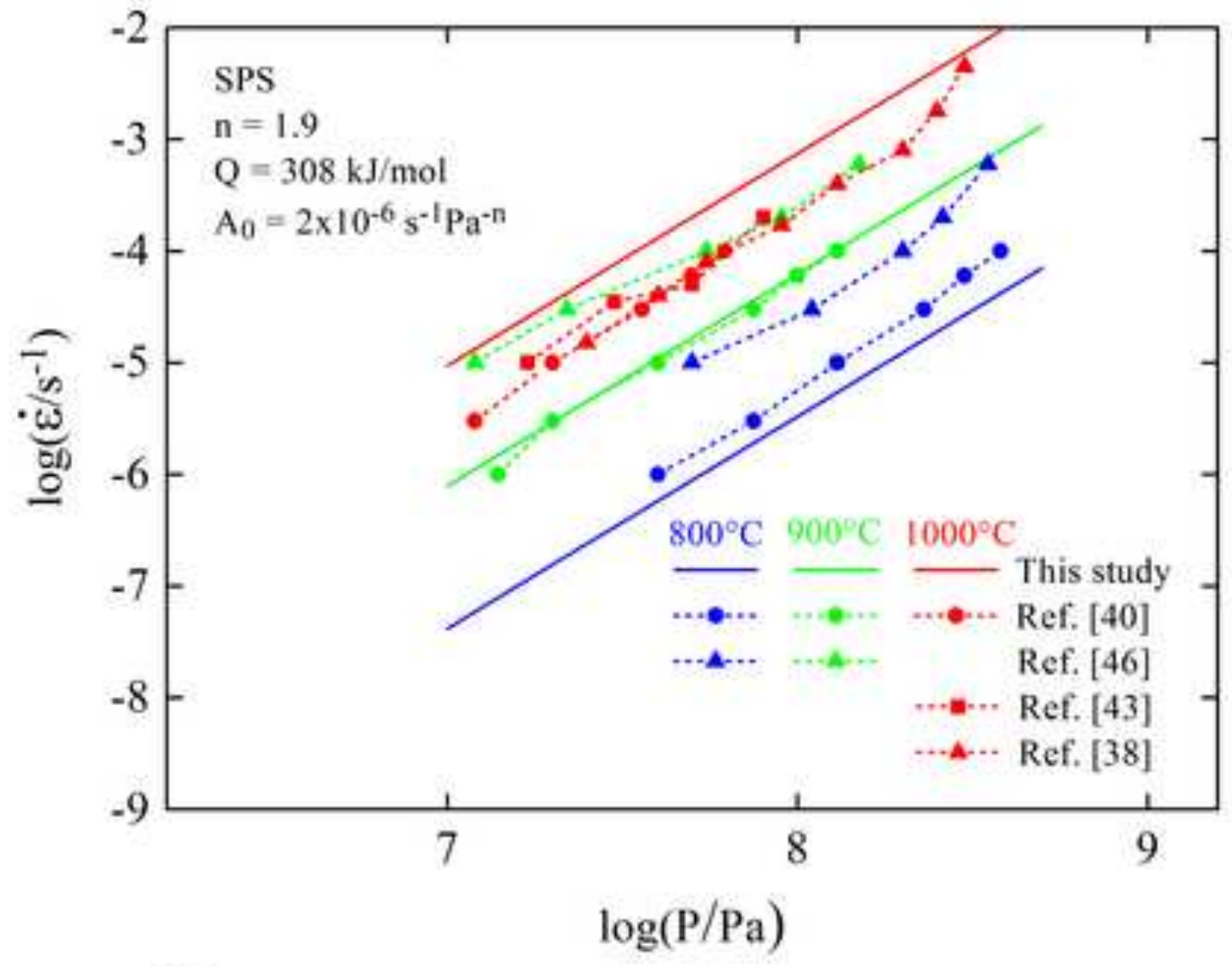

(b)

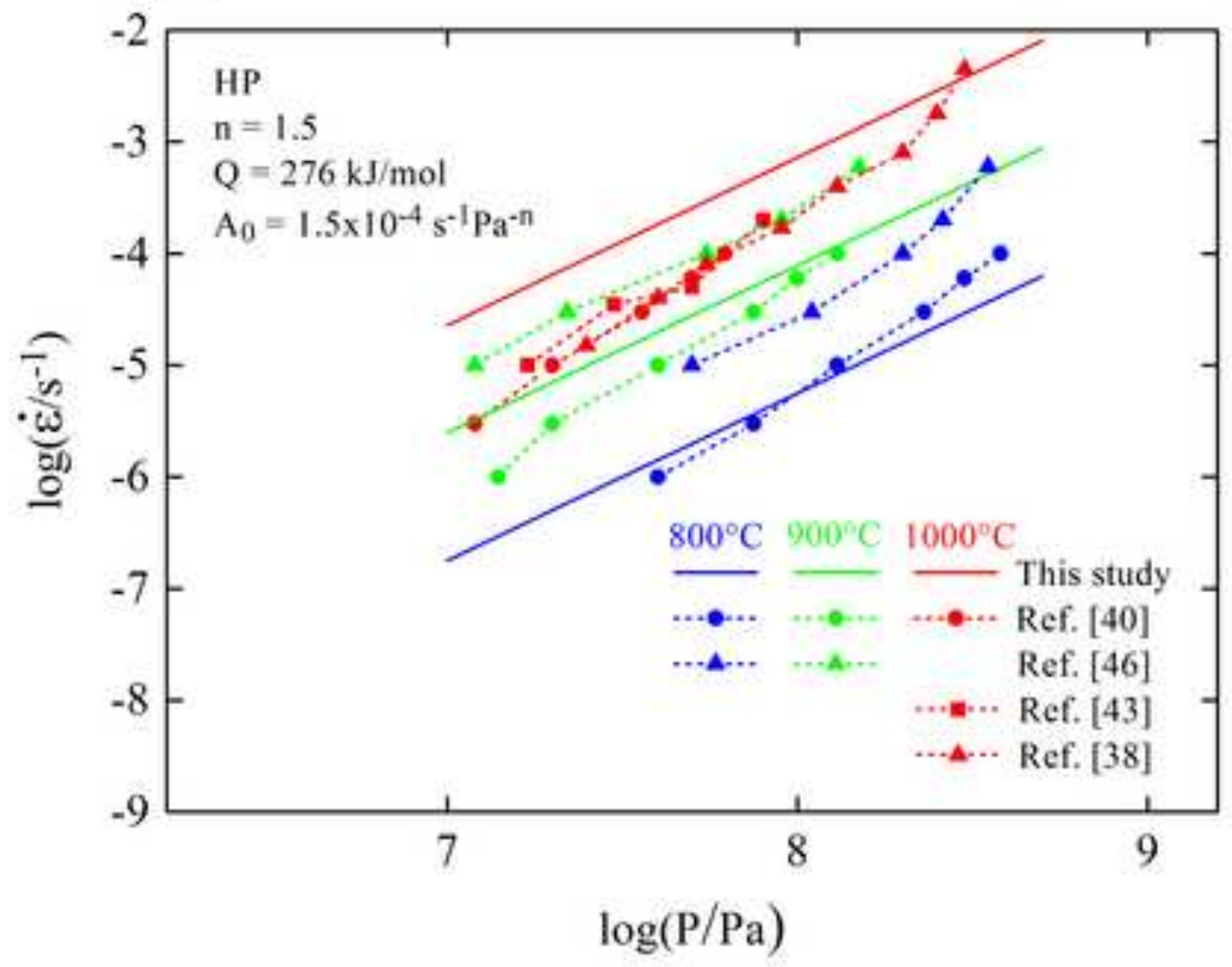




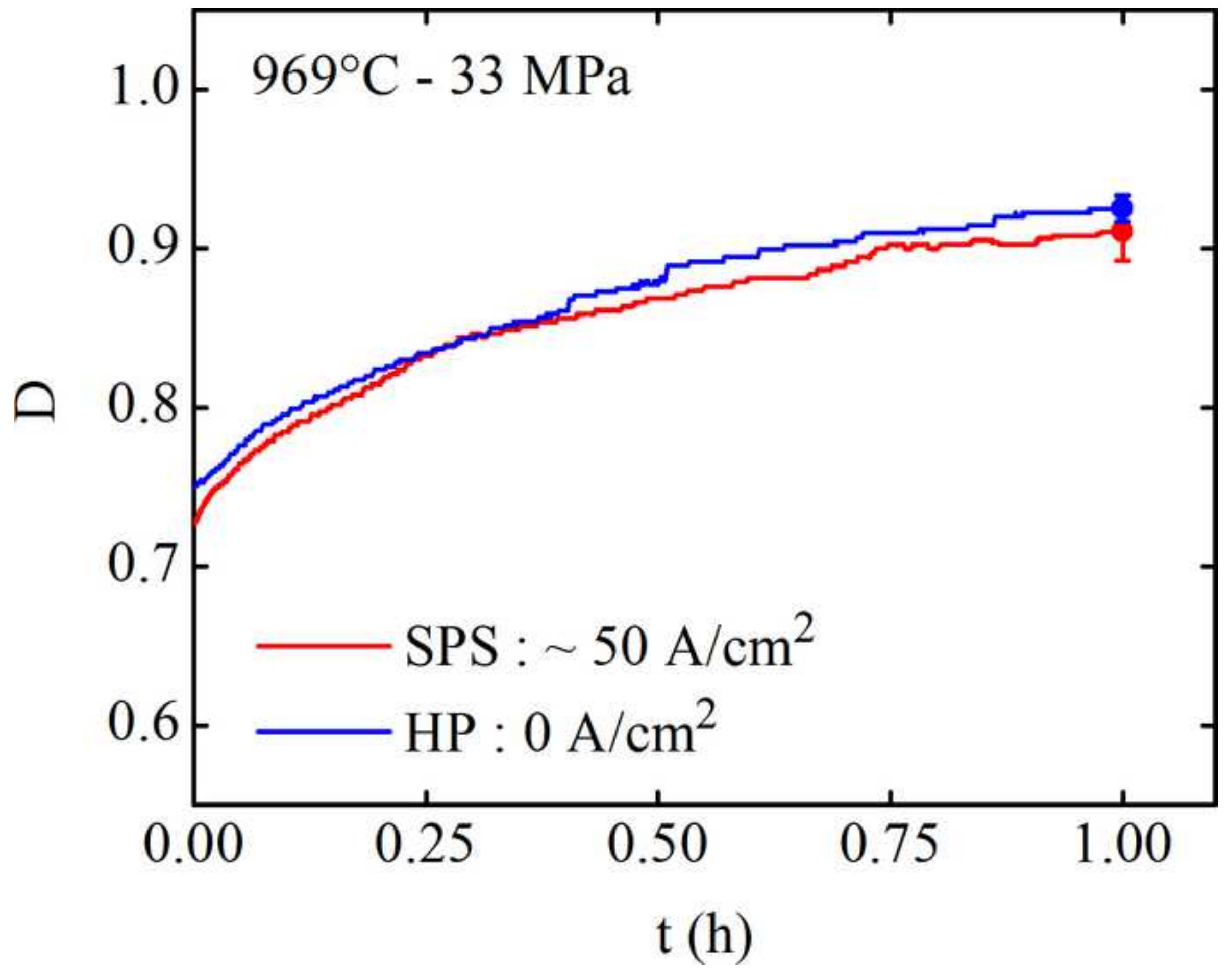

